\title{
The Atmospheric Moisture Residence Time and Reference Time for Moisture Tracking over China
}

\author{
NING WANG \\ College of Hydrology and Water Resources, Hohai University, and College of Meteorology and Oceanography, \\ National University of Defense Technology, Nanjing, Jiangsu, China \\ XIN-MIN ZENG \\ College of Hydrology and Water Resources, Hohai University, and Key Laboratory for Mesoscale Severe Weather of \\ Ministry of Education, Nanjing University, Nanjing, Jiangsu, China \\ YiQUN ZHENG, JIAN ZHU, AND SHANHU JiANG \\ College of Hydrology and Water Resources, Hohai University, Nanjing, Jiangsu, China
}

(Manuscript received 30 October 2017, in final form 19 May 2018)

\begin{abstract}
This paper studies the atmospheric moisture residence times over China for the period 1980-2009 using the dynamic recycling model (DRM). We define both the residence times for atmospheric moisture of precipitation (backward tracking) and evaporation (forward tracking) and show that each has significant spatial and seasonal variations. The area-averaged precipitation-moisture residence time is approximately 8.3 days, while the evaporation residence time is approximately 6.3 days. In addition, we investigate the concept of "tracking time" or time selected for moisture tracking in numerical source-sink studies. The area-averaged backward and forward tracking times at the $90 \%$ threshold (i.e., when $90 \%$ of initial moisture is attributed for tracking) are approximately 22 and 15 days, respectively. Finally, we theoretically deduced the explicit expressions for residence and tracking times for idealized cases and found the analytical proportional relationship between these times. In this way, the analytical link between residence time and $e$-folding time was reestablished. This proportional relationship was further verified against the DRM-derived values. In the DRM results, the proportional relation generally fluctuates along the trajectory, which leads to the differences between the theoretical and the DRM-derived values. These results can enhance our understanding of water cycling, and they are likely to help choose tracking times in relevant studies.
\end{abstract}

\section{Introduction}

The atmospheric moisture residence time, defined as the time between when moisture evaporates from and returns to the surface as precipitation, is a fundamental characteristic of the atmospheric hydrologic cycle (Läderach and Sodemann 2016; van der Ent and Tuinenburg 2017). In addition to evaporation and precipitation rates, the residence time is an indicator of the atmospheric moisture-holding capacity and provides information about how climate change modifies dynamic processes in the hydrological cycle and water balance (Läderach and Sodemann 2016).

\footnotetext{
Corresponding author: Xin-Min Zeng, zen_xm@yahoo.com
}

The reference time for moisture tracking (hereafter, "tracking time" for simplicity) is the time selected for moisture tracking when exploring moisture sources for precipitation or moisture sinks for evaporation using the moisture-tracking methods. Generally, the proportion of attributed moisture to initial moisture increases and would be infinitely close to 1 with the increase of tracking time (Dominguez et al. 2006; Dirmeyer and Brubaker 2007). Therefore, the tracking time does not have fixed and deterministic boundaries but should rather depend on a threshold of the proportion of attributed moisture to initial moisture.

Assuming a depletion rate $\lambda$ and that the change in precipitable water $(\mathrm{Pw})$ only depends on precipitation, $\lambda^{-1}$, which equals the precipitable water divided by precipitation rate and corresponds to the $e$-folding time 
constant (i.e., the time during which precipitation depletes the global precipitable water to $1 / e$ of the initial amount), is regarded as the depletion time (Trenberth 1998; Bosilovich et al. 2005). Similarly, when assuming that $\lambda$ represents the recharge rate and that the change in precipitable water only depends on evaporation, the restoration time constant $\lambda^{-1}$ equals the precipitable water divided by the evaporation rate (Trenberth 1998). Therefore, several studies have obtained the moisture depletion (restoration) time by the method of dividing the atmospheric water by the precipitation (evaporation) rate, which is termed the traditional bulk method in this study. Researchers van der Ent and Tuinenburg (2017) noted that this method is valid when used to calculate the global average atmospheric moisture residence time, since the only inflow is evaporation and the only outflow is precipitation for the entire atmosphere. With the traditional bulk method, Trenberth (1998) indicated the global average depletion and restoration time values of 9.1 and 8.9 days, respectively, and argued that the difference is caused by errors in the data that are used. Subsequently, the global average moisture residence time of 8-10 days was also obtained by several other studies with the same method but different datasets (e.g., Savenije 2000; Douville et al. 2002; Hendriks 2010; Bodnar et al. 2013; van der Ent and Tuinenburg 2017).

The $e$-folding time constant was obtained and regarded as the residence time in several studies by investigating the depletion process of the initial moisture from a model perspective. For example, a special experiment, in which all the initial atmospheric water was tagged, was performed to obtain the $e$-folding time constant by turning off the evaporation of passive water tracers in an atmospheric general circulation model (Bosilovich and Schubert 2002; Bosilovich et al. 2002, 2005). The global mean $e$-folding time constant was found to be 8.5 days in May by Bosilovich and Schubert (2002) and 9.2 days in an undefined period by Bosilovich et al. (2002, 2005). Yoshimura et al. (2004) performed a similar experiment with an offline Eulerian moisture tracking model and found the global mean residence time is between 7.3 (April) and 9.2 days (August).

Using a Lagrangian tracking method termed 3D-T, Tuinenburg et al. (2012) presented probability density functions of the residence times for moisture evaporated from the Ganges basin, which are determined by the time after evaporation of a water parcel and the amount of water that precipitated out of the parcel during each time step. They found that the residence time of approximately 5 days for evaporated moisture has the highest probability, but that much evaporation still resides in the atmosphere after more than 25 days. In a near-global study, van der Ent et al. (2014) calculated the age of tagged continental precipitation and evaporation by extending an offline Eulerian moisture tracking model [Water Accounting Model-2 layers (WAM-2layers); van der Ent 2014]. They found that the mean residence times of land precipitation and evaporation are 9.7 and 8.7 days, respectively. Using the Lagrangian tracking model FLEXPART (Stohl et al. 2005) to identify moisture sources for precipitation, Läderach and Sodemann (2016) obtained the residence time of the precipitation event by averaging the time between evaporation and final precipitation and weighted it by the contribution of each evaporation event to the final precipitation. They found the global mean moisture residence time to be 4-5 days, which is, approximately, only half of the traditional 8-10 days' estimate. However, van der Ent and Tuinenburg (2017) argued that the $4-5$ days' estimate obtained by Läderach and Sodemann (2016) should be incorrect, and they obtained the global mean moisture residence time of 8.5 days by using WAM-2layers (van der Ent 2014) and 3D-T (Tuinenburg et al. 2012).

Although almost all the previous studies have suggested that the global mean moisture residence time should be $8-10$ days, the local moisture residence time can vary significantly with space and time (Yoshimura et al. 2004; van der Ent and Tuinenburg 2017) and can be as long as more than 25 days or as short as several hours (Tuinenburg et al. 2012; Wei et al. 2016) due to different weather conditions in the transport process. Trenberth (1998) also used the traditional bulk method and local moisture-related variables (i.e., atmospheric moisture storage and precipitation and evaporation rates) to calculate the local depletion and restoration times which, however, cannot be regarded as actual local residence times because the method does not consider the horizontal moisture flux (van der Ent and Tuinenburg 2017). Van der Ent and Savenije (2011) interpreted the local residence times calculated by Trenberth (1998) as the local moisture recycling time scales and metrics for the local land-atmosphere moisture feedback. The actual local precipitation and evaporation residence times, which are defined in the restoration and depletion perspectives and emphasize the time from the previous evaporation and the time to the next precipitation events (van der Ent and Tuinenburg 2017), can be calculated by moisture backward and forward tracking, respectively (e.g., Läderach and Sodemann 2016; van der Ent and Tuinenburg 2017). The values of the local precipitation residence time by Läderach and Sodemann (2016) are apparently less than that of van der Ent and Tuinenburg (2017), despite that the spatial patterns in both studies are very similar. Läderach and Sodemann (2016) suggested that the local precipitation residence time ranges from less than 2 to more than 8 days in space, while van der Ent and Tuinenburg (2017) obtained the values ranging from less than 5 days to more than 15 days. 
On climatological time scales, the residence time of moisture can be regarded as an inherent property of the hydrologic cycle. However, the results derived from different datasets and tracking methods are different because of differences in data precision as well as assumptions and formulations in the methods. In addition to generally significant differences in the residence time among different studies [e.g., between Läderach and Sodemann (2016) and van der Ent and Tuinenburg (2017)], even results derived from the two different tracking methods with the ERA-Interim datasets (Dee et al. 2011) can have apparent differences in some regions such as China, as shown in Fig. S1 in van der Ent and Tuinenburg (2017). Thus, the actual residence times should be validated by several different methods or models, for example, the dynamic recycling model (DRM; Dominguez et al. 2006; Martinez and Dominguez 2014), which is regarded as one of the state-of-the-art analytical models for moisture tracking (Gimeno et al. 2012) and has not yet been used to estimate the residence time. In addition, almost all the previous studies for local moisture residence times (e.g., Trenberth 1998; van der Ent et al. 2014; Läderach and Sodemann 2016; van der Ent and Tuinenburg 2017) have presented global/nearglobal analyses, in which the detailed characteristics of a certain region (e.g., China) have been overlooked. Thus, it is necessary to focus on certain regions for the details of the atmospheric moisture residence time.

Closely related with the residence time, the tracking time has previously been little researched as a focus of study. The upper bound of the global average moisture residence time, that is, 10 days, was taken as the tracking time in many studies (e.g., Nieto et al. 2006; Gimeno et al. 2010; Drumond et al. 2011; Chen et al. 2012; Sun and Wang 2015; Huang and Cui 2015), and longer periods (15-20 days) were used by other studies (e.g., Dirmeyer and Brubaker 1999, 2007; Sodemann et al. 2008; Wei et al. 2012; Viste and Sorteberg 2013; Zhang and $\mathrm{Li}$ 2014). However, as previously mentioned, the residence time is also the $e$-folding time under several assumptions, which means that there should still be approximately $1 / e$ of initial moisture that remains after tracking the moisture for a period of the residence time. In this context, taking the residence time as the tracking time appears too short and unreasonable to some extent and hence may overlook some important moisture sources or sinks. Bosilovich and Schubert (2002) found that after tracking the moisture for 30 days, there still remains $3 \%$ of tagged evaporation in the atmosphere. It can be estimated that the ratio of the remaining initial evaporation reaches approximately only $30 \%$ (i.e., $70 \%$ of the initial evaporation has been rained out) after approximately 10 days' tracking and that there still exists approximately $2 \%$ of the initial moisture after 30 days' tracking, as inferred from Fig. 2 by Yoshimura et al. (2004). Zhang et al. (2017) also indicated that there is still a considerable amount of tagged moisture in the air after a month's tracking when they studied the moisture source of the Tibetan Plateau. Recently, Wang et al. (2018) found an important moisture source that was previously overlooked for the Yangtze River basin when tracking the moisture for a longer time (i.e., 40 days) than the tracking time in previous studies [e.g., 15 days in Wei et al. (2012) and 10 days in Sun and Wang (2015)]. Thus, here arises a question: what is the appropriate tracking time? In other words, because there always remains a certain amount of initial moisture, how long would it take for the initial moisture with an appropriate proportion (e.g., $90 \%$ ) to be transformed into another form of moisture (i.e., precipitation or evaporation)?

In addition, if the moisture residence time itself cannot be used as the tracking time, the choice of a proper tracking time, which may lead to better estimation of moisture sources or sinks, should rely on the moisture residence time and its certain relationship with the moisture tracking time. Such a relationship seems to exist intuitively but remains to be investigated because both the moisture residence time and the tracking time are closely related with moisture tracking processes.

Therefore, the objective of this paper is twofold: to study the atmospheric moisture residence time and tracking time using the DRM (Dominguez et al. 2006; Martinez and Dominguez 2014) and to investigate the relationship between these two kinds of time. The rest of this paper is organized as follows: section 2 introduces the data and methods used in this study, section 3 presents the results, and section 4 provides the conclusions and discussion.

\section{Data and methods}

\section{a. Data}

In this study, we used the 30-yr (1980-2009) 6-hourly National Centers for Environmental Prediction (NCEP) Climate Forecast System Reanalysis (CFSR; Saha et al. 2010). Geophysical fields used in this study include latent heat flux, surface pressure, precipitation, zonal and meridional wind speeds, and specific humidity. The atmospheric data (i.e., specific humidity and zonal and meridional wind speeds) are available on $0.5^{\circ} \times 0.5^{\circ}$ horizontal grids with 37 pressure levels from 1000 to $1 \mathrm{hPa}$. Precipitation data are provided at the same horizontal resolution. The resolution of latent heat flux and surface pressure data is $0.3125^{\circ}$, but for analysis, we bilinearly interpolated the data onto the same $0.5^{\circ}$ grid. 
Zonal and meridional wind speeds, specific humidity, and surface pressure were used to calculate precipitable water and moisture-weighted vertically integrated zonal and meridional wind fields. The latent heat flux was used to calculate total evapotranspiration, which is not provided explicitly by CFSR (Lorenz and Kunstmann 2012).

\section{b. Method}

The DRM proposed by Dominguez et al. (2006) was used to obtain the residence time and tracking time in this study. The DRM was initially proposed to calculate the precipitation recycling ratio (Dominguez and Kumar 2008; Dominguez et al. 2008) and was subsequently modified by Martinez and Dominguez (2014) to calculate the moisture source of precipitation (e.g., $\mathrm{Hu}$ and Dominguez 2015; Dominguez et al. 2016; Hoyos et al. 2018). The DRM was directly derived from the vertically integrated water balance equation, and it explicitly incorporates the moisture storage term that was neglected in previously relevant models (e.g., Budyko 1974; Brubaker et al. 1993; Eltahir and Bras 1994). In the DRM, the contribution of evaporation along the backward trajectory to precipitation for a grid cell (i.e., precipitation recycling ratio) is expressed as

$$
\rho(t)=1-\exp \left(-\int_{0}^{t} \frac{E}{w} \partial t^{\prime}\right), \quad t \geq 0,
$$

where $E$ and $w$ are the evaporation rate and atmospheric precipitable water along the trajectory, respectively. According to Martinez and Dominguez (2014), the proportion of attributed precipitation along the trajectory during a time step $\Delta t$ to precipitation at a grid can be calculated by

$\Delta \rho(t)=\exp \left(-\int_{0}^{t-\Delta t} \frac{E}{w} \partial t^{\prime}\right) \times\left[1-\exp \left(-\int_{t-\Delta t}^{t} \frac{E}{w} \partial t^{\prime}\right)\right]$.

Similarly, van der Ent and Savenije (2011) gave the expression of the proportion of evaporation returning to the surface due to precipitation along the forward trajectory, that is, the evaporation recycling ratio (van der Ent et al. 2010) as

$$
\varepsilon(t)=1-\exp \left(\int_{0}^{t} \frac{P}{w} \partial t^{\prime}\right), \quad t \leq 0
$$

or

$$
\varepsilon(t)=1-\exp \left(-\int_{0}^{t} \frac{P}{w} \partial t^{\prime}\right), \quad t \geq 0,
$$

where $P$ is the precipitation rate along the trajectory. Applying a similar method [i.e., to obtain Eq. (2) from
Eq. (1) in Martinez and Dominguez (2014)] to Eq. (4), we can compute the proportion of evaporation returning to the surface, that is, the proportion of attributed evaporation along the trajectory during a time step by

$\Delta \varepsilon(t)=\exp \left(-\int_{0}^{t-\Delta t} \frac{P}{w} \partial t^{\prime}\right) \times\left[1-\exp \left(-\int_{t-\Delta t}^{t} \frac{P}{w} \partial t^{\prime}\right)\right]$.

Then, the moisture residence time of the initial moisture is weighted by the proportion of attributed moisture during each time step and averaged over the tracking time (Läderach and Sodemann 2016), which can be explicitly expressed as

$$
T_{P-\operatorname{Res}}=\frac{\sum t \Delta \rho(t)}{\sum \Delta \rho(t)}
$$

and

$$
T_{E-\operatorname{Res}}=\frac{\sum t \Delta \varepsilon(t)}{\sum \Delta \varepsilon(t)}
$$

where $T_{P \text {-Res }}$ and $T_{E \text {-Res }}$ are the atmospheric residence times of precipitation and evaporation, respectively. To better understand Eqs. (6) and (7), Fig. 1 shows a diagram representing the evaporation residence time [Eq. (7)]. During each time step $\Delta t$, a proportion of initial evaporation returns to the surface, and the residence time of this portion is the current tracking time (i.e., from the beginning to this time step), for example, the moisture returning to the surface during the first time step has the residence time of $\Delta t$. In that sense, Eq. (7) can be interpreted as the calculation of the average residence times of all moisture from the initial evaporation event. In a similar manner, if we move backward in time from a given precipitation event, Eq. (6) can be interpreted as the average residence time of the evaporation that contributed to the given precipitation event. Note that the residual moisture always exists after the end of the trajectories, and the calculations of Eqs. (6) and (7) also implicitly include the method of dealing with the residual moisture that is proportionally assigned to the former contributions during each time step, following Dirmeyer and Brubaker (2007).

We performed two experiments with the DRM. In the first experiment, we tracked the precipitation over China backward to its origin to calculate the residence time of precipitation and the backward tracking time. In the second experiment, we tracked the evaporation over China forward to its destination to calculate the residence time of evaporation and forward tracking time. In these experiments, the time for moisture tracking is 


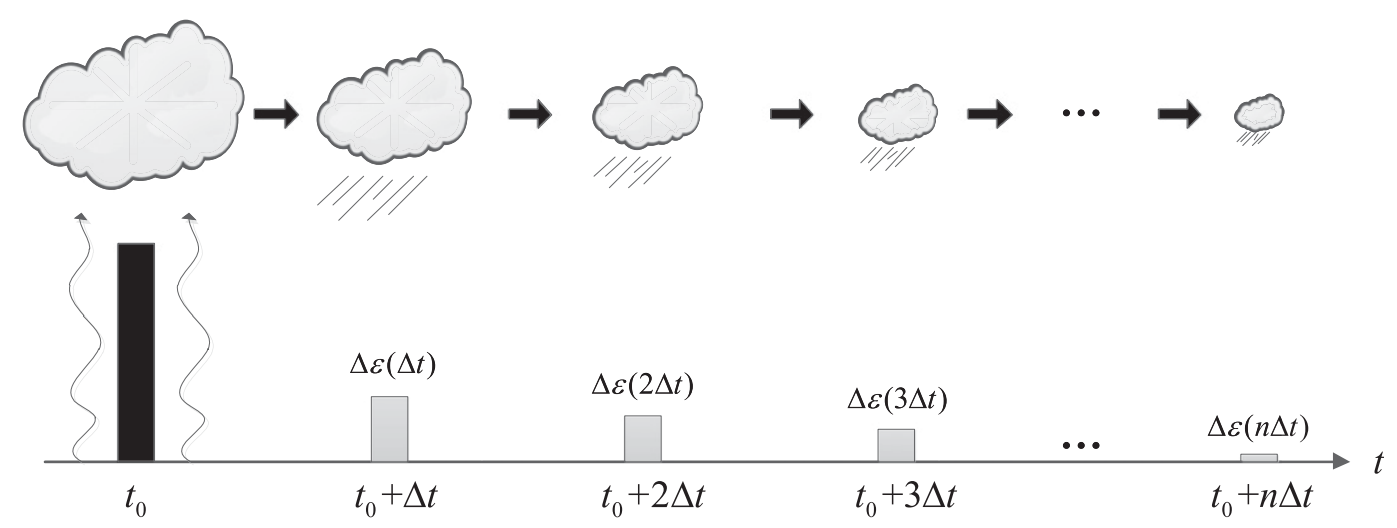

FIG. 1. Schematic of the process of evaporated moisture to be attributed by the following precipitation events during each time step.

30 days [i.e., the same period as that used by van der Ent and Tuinenburg (2017)] with a time step of $1 \mathrm{~h}$ (the 6-hourly data were linearly interpolated to an hourly resolution for moisture tracking).

\section{Results}

\section{a. Moisture arriving in and leaving China}

Climatically, China has different large-scale circulation patterns in the winter and summer, which are represented by January and July in Fig. 2. In January (Figs. 2a,c), the circulation over China is dominated by a westerly/northwesterly flow. In July (Figs. 2b,d), influenced by the Indian summer monsoon (ISM) and the East Asian summer monsoon (EASM), a southwesterly flow prevails over eastern China, while over western China, the westerly wind still dominates. Therefore, moisture arriving in (leaving) China in January and July has different sources (sinks), as shown in Fig. 3. For any region, the moisture sources (sinks) of precipitation (evaporation) can be divided into the local (i.e., recycling part) and external regions (Burde and Zangvil 2001). The local moisture sources and sinks are important for precipitation and evaporation, especially for the regions with relatively high $E-\mathrm{Pw}$ and $P-\mathrm{Pw}$ ratios (i.e., the ratios of daily evaporation and precipitation to precipitable water, respectively), for example, the Tibetan Plateau (Fig. 2). The external moisture sources (sinks) are generally located in the upwind (downwind) directions of the prevailing flows. However, the spatial distributions of moisture sources and sinks (Fig. 3) do not fully agree with the large-scale circulation patterns (Fig. 2) for the following reasons: 1) the synoptic-scale circulation, which is directly related to the moisture transport and precipitation process, can be quite different from its climatic state (Sun and Wang 2015; Zeng et al. 2018) and 2) the distribution of precipitation (evaporation) over China is quite inhomogeneous. Figure 3 only shows the main moisture sources (sinks) for the total precipitation (evaporation) over China, in which the target regions with low precipitation (evaporation) are given little weight, and thus the sources (sinks) for those low-precipitation (evaporation) regions may be overlooked.

For the moisture sources of precipitation over China in January (Fig. 3a), the main sources are southwest and south China and the adjacent continental and oceanic areas, which are a zonal region from the Arabian Sea (ARS) to the South China Sea (SCS), north of $10^{\circ} \mathrm{N}$, and other sources, such as the Mediterranean Sea, the Black Sea, and the Caspian Sea. During this period, the cold surges associated with the winter monsoon can largely influence the weather conditions over China; this monsoon, however, carries little moisture. One of the important weather systems for water vapor transport to China is the trough that is embedded in the southern branch of the subtropical westerlies south of the Tibetan Plateau, in front of which the southerly wind can bring in moisture evaporated from the ARS-SCS band to southwest and south China (e.g., He et al. 2007; Wen et al. 2009; Lin 2016). Moisture evaporated from the western Pacific Ocean can also be transported to south China by anticyclone systems (Sun and Wang 2015). The prevailing westerly flow can bring moisture evaporated from southwest China to east China (Fig. 2a; Zheng et al. 2002; Chen et al. 2012). In July (Fig. 3b), the main sources extend to much larger areas, which include most of China, the entire north Indian Ocean, and part of the south Indian Ocean. The contributions from adjacent regions of China in summer (Fig. 3b) are much less than in winter (Fig. 3a), which implies that the moisture arriving in China may experience a longer residence time. The monsoon region is largely influenced by the ISM 

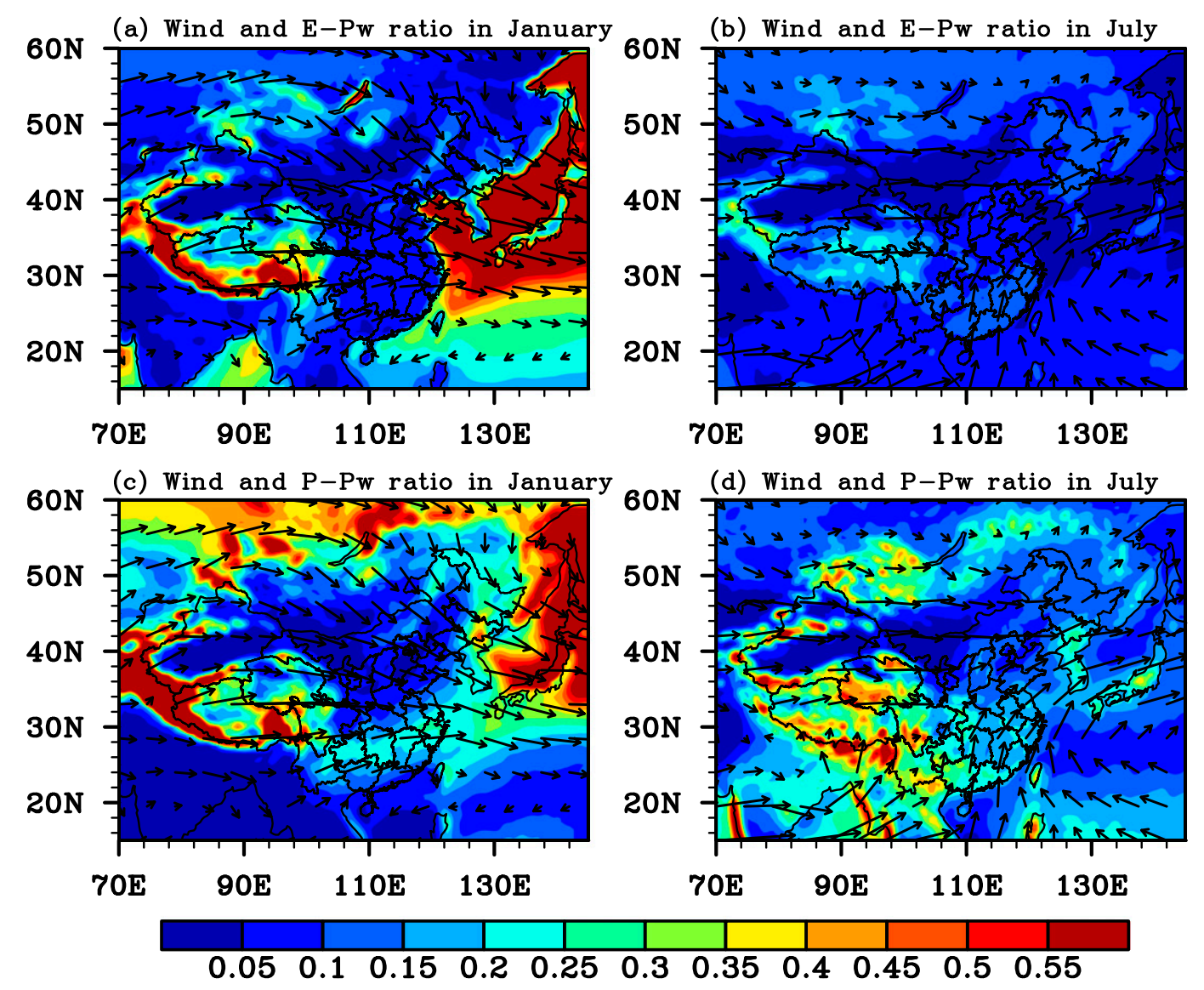

FIG. 2. The 30-yr-averaged moisture-weighted vertically integrated wind and the (top) E-Pw ratio and (bottom) corresponding $P-\mathrm{Pw}$ ratio in (a),(c) January and (b),(d) July.

and EASM (Simmonds et al. 1999; Zhou et al. 2008), and the moisture evaporated from the Indian Ocean, SCS, and the western Pacific Ocean is a major source for summer precipitation over south China (Sun and Wang 2015). However, the oceanic moisture can hardly reach north China because of the losses en route, and evaporation from local and the south terrestrial areas is a main moisture source for summer precipitation over north and northeast China (Sun and Wang 2015; Hu et al. 2018). Meanwhile, southwest China still provides moisture for summer precipitation over east China through the westerly wind, which is similar for winter. Because of the second reason mentioned above, there are some sources that are important for precipitation over subregions of China but unimportant for the total precipitation over China and that cannot be identified in Fig. 3. For example, part of the Eurasia continent in the west and north of China is an important moisture source for precipitation over north China and the Tibetan Plateau both in summer and winter (e.g., Sun and Wang 2014; Hu et al. 2018; Hua et al. 2017b; Zhang et al. 2017).
For the moisture sinks of evaporation from China, the main sinks in January (Fig. 3c) and July (Fig. 3d) show some similarities and differences in their spatial patterns. East and south China and the northwestern Pacific Ocean are the primary moisture sinks both in winter and summer. However, the intensities over these two sinks are quite different, with more evaporation precipitating in China and the northwestern Pacific Ocean in January (Fig. 3c) and July (Fig. 3d), respectively. In January, the oceanic areas east of China with relatively high $P-\mathrm{Pw}$ ratios (Fig. 2c) are a major moisture sink (Fig. 3c). In particular, most of the evaporation from north and northeast China quickly precipitates in the nearby Sea of Japan and the northwestern Pacific Ocean because of the prevailing northwesterly wind and very high $P-\mathrm{Pw}$ ratios over those regions (Fig. 2c). Part of the evaporation from southwest and south China precipitates in local regions and east China, as is addressed above, and the other part, together with the evaporation from east China, is transported to and precipitates in the northwestern Pacific Ocean. Evaporation from northwest China may traverse the eastern land areas, where the $P-\mathrm{Pw}$ 
(a) Moisture sources in January

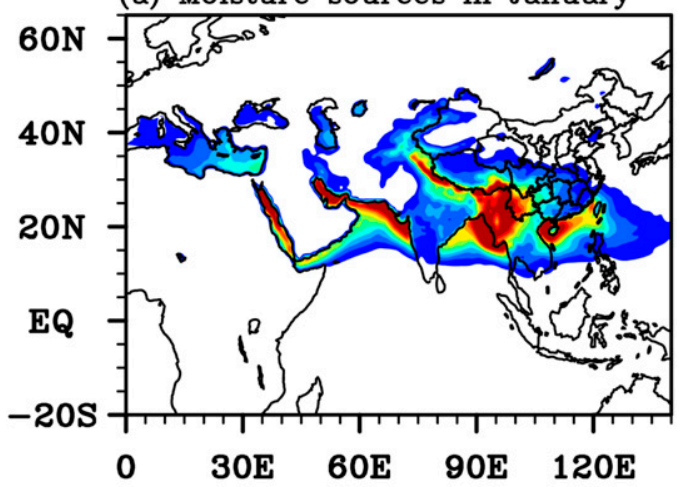

(c) Moisture sinks in January

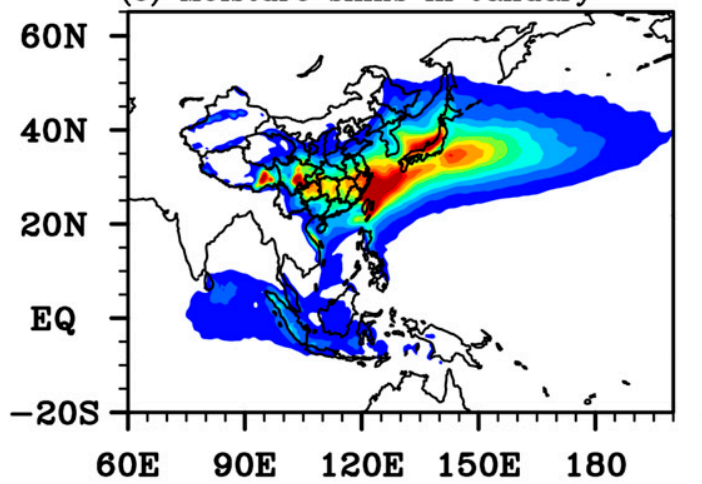

(b) Moisture sources in July

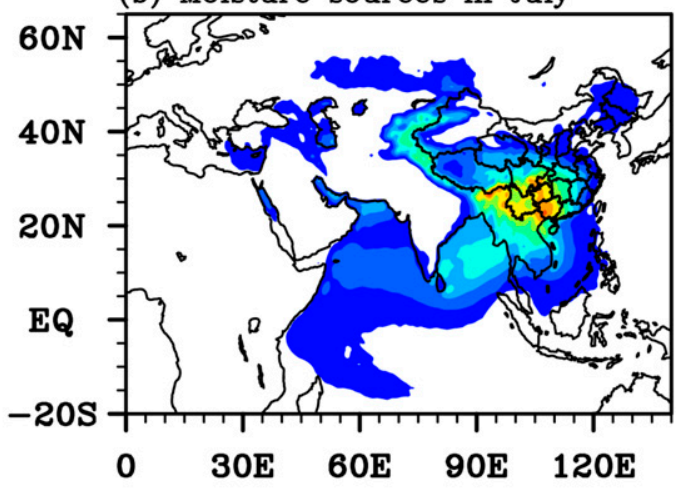

(d) Moisture sinks in July

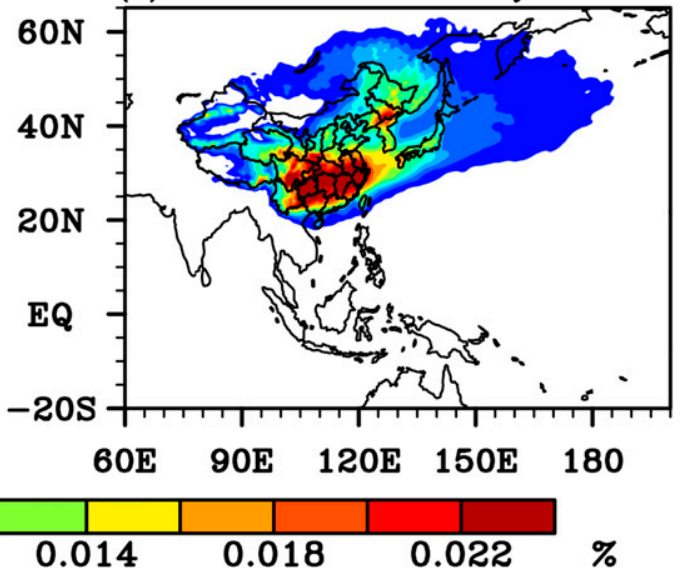

FIG. 3. The 30-yr-averaged (top) moisture sources for total precipitation and (bottom) moisture sinks for total evaporation over China in (a),(c) January and (b),(d) July. The moisture sources (sinks) are denoted as the percentage of attributed precipitation (evaporation) to total precipitation (evaporation) by each grid cell.

ratio is very low (Fig. 2c), and finally precipitates in the oceanic areas east of China. Additionally, part of evaporation from China can precipitate in the equatorial Indian Ocean (Fig. 3c) and may be transported by the northeasterly winds associated with the strong cold surges. In July, however, a large part of the evaporation from southwest and south China can precipitate in the local and adjacent downstream regions of east China (Fig. 3d) due to the high $P-\mathrm{Pw}$ ratios and low wind speeds over those regions (Fig. 2d), and the residual evaporation can precipitate in farther northeastern regions, for example, north and northeast China and the northwestern Pacific Ocean; evaporation from north and northeast China can be transported to the high-latitude regions and may reside in the atmosphere for a longer time due to the relatively low $P-\mathrm{Pw}$ ratios over those regions (Fig. 2d).

\section{b. The atmospheric moisture residence time}

Figure 4 shows 30-yr annual residence times of precipitation and evaporation (i.e., $T_{P \text {-Res }}$ and $T_{E \text {-Res }}$, respectively) over China. Compared to previous studies, these results (Fig. 4) are very similar to those by van der Ent and Tuinenburg (2017) in spatial patterns with slightly lower values over China, and thus they indirectly support the traditional global mean estimates of 8-10 days with a different method and a different dataset. The slightly lower values may be attributed to 1) the inherent differences in the tracking methods and datasets and 2) the differences in dealing with the unattributed moisture after the end of the trajectories. Concerning the latter, the residual moisture was assumed to have a residence time of 30 days by van der Ent and Tuinenburg (2017), while we scaled the attributed moisture of each time step.

Spatially, the values of $T_{P \text {-Res }}$ and $T_{E \text {-Res }}$ were shown to be 7-10 and 4-8 days, with averages of approximately 8.3 and 6.3 days (Fig. 4), respectively, indicating that the evaporation from China generally experiences a faster process of raining out than the evaporation from sources for precipitation over China. This can be explained by the fact that precipitation is generally larger than evaporation over China (Fig. 2), which would cause 


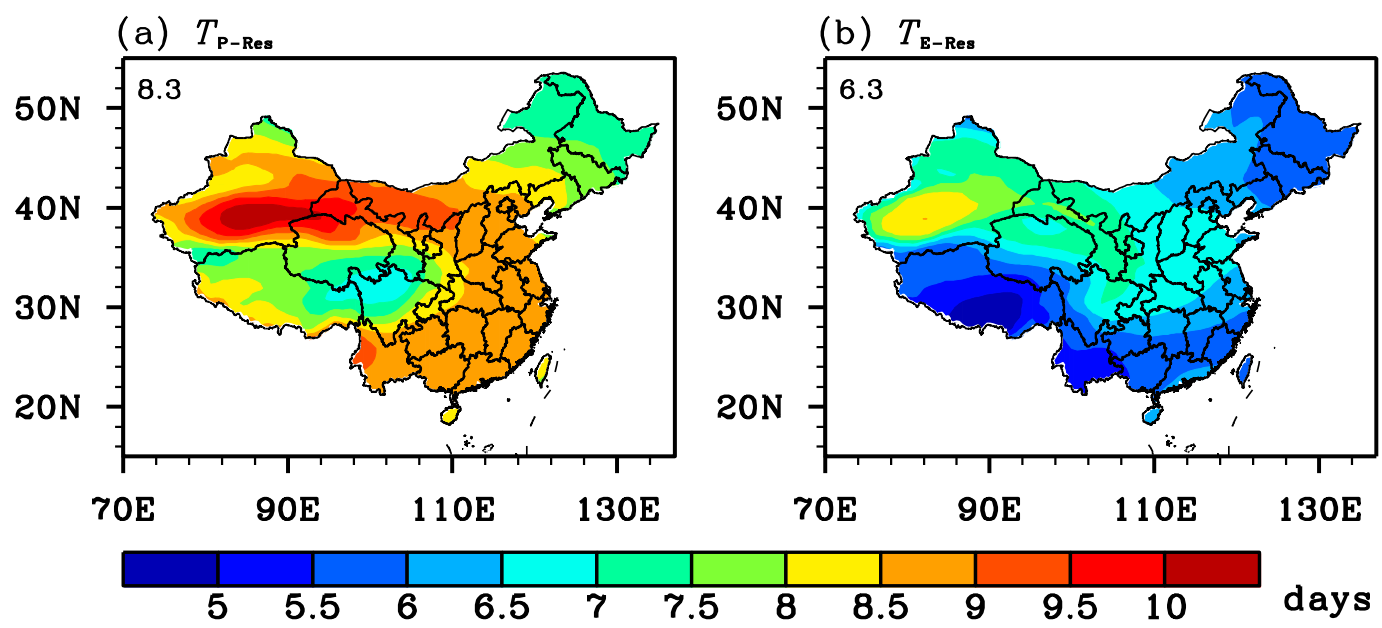

FIG. 4. The 30-yr annual average atmospheric moisture residence times, with the area-averaged values denoted in the upper-left corners: (a) $T_{P \text {-Res }}$ and (b) $T_{E \text {-Res }}$.

local regions to account for more evaporation compared to precipitation (Fig. 3). Although $T_{P \text {-Res }}$ is generally 2-3 days longer than $T_{E \text {-Res }}$, their spatial patterns show some similarity to each other (with a correlation coefficient of 0.50). For example, both $T_{P \text {-Res }}$ and $T_{E \text {-Res }}$ values are relatively low over the Tibetan Plateau (Fig. 4). The reason for this is that both the $E-\mathrm{Pw}$ and $P-\mathrm{Pw}$ ratios over the Tibetan Plateau are relatively high throughout the year (Fig. 2), which leads to a greater proportion of precipitation and evaporation over this region that can be attributed locally within a very short period compared to other regions. The relatively high $E-\mathrm{Pw}$ ratios over the Tibetan Plateau, together with the prevailing westerly wind (Figs. 2a,b), can also explain the minimal $T_{P \text {-Res }}$ values over the east edge of the Tibetan Plateau (Fig. 4a), over which a considerable proportion of moisture comes from the adjacent Tibetan Plateau. Relatively high values of both $T_{P \text {-Res }}$ and $T_{E \text {-Res }}$ can be found over the arid and semiarid regions, such as the Tarim basin, the Qaidam basin, the Hexi Corridor, and the west Inner Mongolia region (Fig. 4). Note that the arid and semiarid areas (e.g., the Tibetan Plateau) do not necessarily show relatively long residence times (Fig. 4). The highest $T_{P \text {-Res }}$ and $T_{E \text {-Res }}$ values appear over the Tarim basin (Fig. 4) - an extremely arid regionwhich can be attributed to the very little evaporation and rare precipitation events over this region. Theoretically, a larger $T_{P \text {-Res }}$ value indicates that moisture over a given area generally comes from more remote sources, while a larger $T_{E \text {-Res }}$ value indicates that moisture over a given area goes to more remote sinks. Thus, a longer residence time may be in agreement with a lower moisture recycling ratio, and vice versa. For example, the Tibetan Plateau, with a relatively small
$T_{P \text {-Res }}($ Fig. 4a), actually corresponds to a relatively high precipitation recycling ratio (e.g., Hua et al. 2017a).

The higher $T_{P \text {-Res }}$ values over the arid regions appear to be different from the result by van der Ent and Tuinenburg (2017), who suggested that the low $T_{P \text {-Res }}$ values exist mostly over the regions with low precipitation. In fact, both results are reasonable. Note that van der Ent and Tuinenburg (2017) also stated that the low precipitation does not necessarily coincide with low $T_{P \text {-Res }}$ values. Looking carefully at their results (e.g., Fig. 2 by van der Ent and Tuinenburg 2017), we find that all the areas with both low precipitation and low $T_{P \text {-Res }}$ are oceanic areas, but the much smaller areas, the continents, always have high $T_{P \text {-Res }}$ values with low precipitation (e.g., the Sahara, the Arabia, and northwest China), as is also shown in the present study. The reason for the opposite results between the oceans and continents is that the oceanic areas with low precipitation often correspond to high evaporation levels that can provide abundant moisture for local precipitation, while the continental areas with low precipitation are generally accompanied by low evaporation (Dirmeyer et al. 2009). However, as previously stated, not all of the continental areas with low precipitation have high $T_{P \text {-Res }}$ values, for example, the characteristic of low precipitation and low $T_{P \text {-Res }}$ over the Tibetan Plateau is caused by the low precipitable water over the region [Eq. (6)].

In addition to the spatial variability (Fig. 4), the residence time also has an apparent seasonal variation as presented in Fig. 5. Despite the seasonal variations, the $T_{P \text {-Res }}$ values are generally higher than those of $T_{E \text {-Res }}$ in the corresponding months (Fig. 5), as is consistent with the annual results (Fig. 4). Generally, the $T_{P \text {-Res }}$ values 

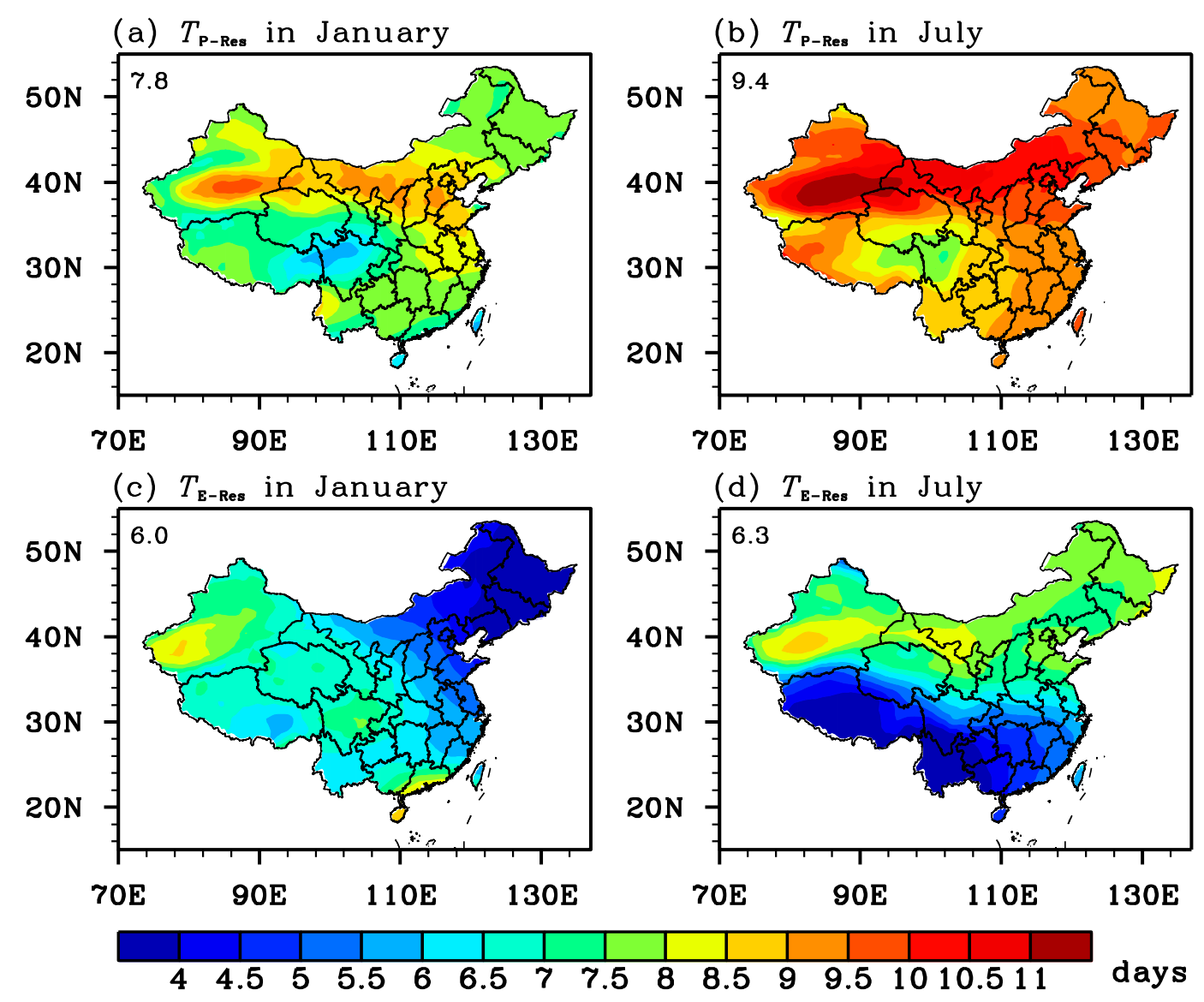

FIG. 5. The 30-yr-averaged (top) $T_{P \text {-Res }}$ and (bottom) $T_{E \text {-Res }}$ for (a),(c) January and (b),(d) July, with the areaaveraged value denoted in the upper-left corner.

for July are 1-2 days longer than those for January (Figs. 5a,b). The area-averaged $T_{P \text {-Res }}$ (i.e., 7.8 and 9.4 days for January and July, respectively) suggest that the previous evaporation for precipitation resides longer in July than in January over China, which corresponds to the fact that the moisture sources are closer to China in January than July (Figs. 3a,b). Both the January (Fig. 5a) and July (Fig. 5b) patterns are very similar to the annual pattern (Fig. 4a; with the correlation coefficients of 0.73 and 0.66 , respectively), indicating the seasonal variability of the spatial $T_{P \text {-Res }}$ pattern is insignificant in this context.

Compared to $T_{P \text {-Res }}$, the area-averaged $T_{E \text {-Res }}$ has little seasonal variation (Figs. $5 \mathrm{c}, \mathrm{d}$ ), for example, the values are 6.0 and 6.3 days for January and July, respectively. However, the spatial $T_{E \text {-Res }}$ patterns for January and July are substantially different and even contrary to each other in some regions. For example, the values over northeast China and southwest and south China show opposite characteristics for January in contrast with those for July. For January (Fig. 5c), the values over northeast China are relatively low. For July (Fig. 5d), however, the relatively low values exist over southwest and south China. The differences in the spatial patterns of $T_{E \text {-Res }}$ in January and July can be attributed to the different circulation patterns and relative variables, as analyzed in section $3 \mathrm{a}$, which make the evaporation from northeast China and southwest and south China precipitate quickly in January and July, respectively.

As a summary for the seasonal variations of both the precipitation and evaporation residence times, $T_{P \text {-Res }}$ varies significantly (insignificantly) in magnitude (spatial pattern), while $T_{E \text {-Res }}$ varies significantly (insignificantly) in spatial pattern (area-averaged value) with season.

\section{c. The reference time for moisture tracking}

The issue of the moisture tracking time, which is important for moisture tracking and is explored in this study, has previously drawn little attention. According to Eqs. (1) and (4), the proportion of attributed moisture increases with the tracking time. Figure 6 presents the 


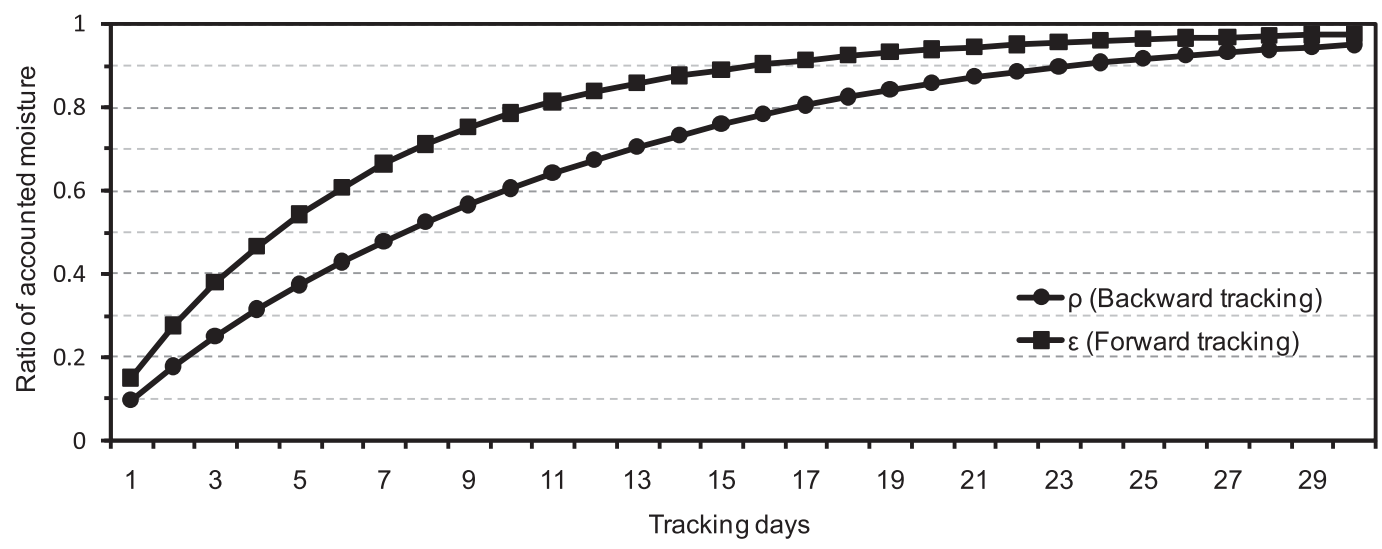

FIG. 6. The 30-yr mean and area-averaged ratios of attributed moisture to initial moisture (i.e., $\rho$ and $\varepsilon$ ) as changing with backward- and forward-tracking days.

area-averaged ratios of attributed moisture to initial moisture of the backward and forward trackings (i.e., $\rho$ and $\varepsilon$ ) as changing with the tracking time. Apparently, $\varepsilon$ appears to increase faster than $\rho$ during the initial stage but reaches approximately equivalent values compared to $\rho$ after 30 days' tracking (Fig. 6). This characteristic corresponds to the fact that more evaporation is attributed in the local and adjacent regions compared to precipitation (Fig. 3) and the shorter $T_{E \text {-Res }}$ value in contrast to the value of $T_{P \text {-Res }}$ (Fig. 4). The ideal situation for moisture tracking is that all the initial moisture is attributed when exploring moisture sources of precipitation or destinations of evaporation with the method of the Lagrangian tracking. However, the ideal situation cannot be reached, and there is no rigorous standard for how much initial moisture should be attributed to previous evaporation or later precipitation in practical studies. Previous Lagrangian tracking studies of moisture sources or sinks generally have attributed most (generally $\sim 90 \%$ ) of the initial moisture with different tracking days (e.g., Sodemann et al. 2008; Tuinenburg et al. 2012; Chen et al. 2013; Sun and Wang 2015). Thus, as an example, we chose $90 \%$ as the threshold for the tracking time in this study, that is, the time periods during which $90 \%$ of the initial moisture is attributed in the moisture tracking. Figure 6 shows that the area-averaged backward and forward tracking times at the threshold of $90 \%$ over China are approximately 22 and 15 days, respectively.

To obtain the climatic spatial patterns of the backward and forward tracking times at the $90 \%$ threshold, we first averaged the ratios of the attributed moisture to the initial moisture with the tracking time for each grid over the 30 years (i.e., 1980-2009) and then obtained the tracking times (for simplicity, $T_{P \text {-Tra }}$ is denoted as the backward tracking time, together with $T_{E \text {-Tra }}$ for the forward tracking time). In comparing the residence times with the tracking times (Fig. 4 vs Fig. 7), the patterns of $T_{P \text {-Res }}$ and $T_{E \text {-Res }}$ are similar to those of $T_{P \text {-Tra }}$ and $T_{E \text {-Tra }}$, respectively, and $T_{P \text {-Tra }}(\sim 18-25$ days $)$ is generally higher than $T_{E \text {-Tra }}(\sim 13-17$ days $)$, which corresponds to a higher $T_{P \text {-Res }}$ and lower $T_{E \text {-Res }}$ (Fig. 4). Similar to the $T_{\mathrm{P}-\mathrm{Res}}$ and $T_{E \text {-Res }}$ results, the highest $T_{P \text {-Tra }}$ and $T_{E \text {-Tra }}$ values exist over the Tarim basin (Fig. 7). In addition, some differences were found, for example, the lowest $T_{P \text {-Res }}$ values were found over the east edge of the Tibetan Plateau (Fig. 4a) in contrast to the lowest $T_{P \text {-Tra }}$ values over northeast China (Fig. 7a), and the $T_{E \text {-Res }}$ values over northeast China are relatively low (Fig. 4b) compared with the relatively high $T_{E \text {-Tra }}$ values over northeast China (Fig. 7b).

Figures 8 and 9 show the seasonal variation of the area-averaged $\rho$ and $\varepsilon$ with the tracking time and the spatial patterns of the backward and forward tracking times at the $90 \%$ threshold, respectively. The areaaveraged $\rho$ values for January are consistently higher than for July with the relatively large differences in the first half of the tracking period (Fig. 8a), which corresponds to the lower $T_{P \text {-Res }}$ in January than July (Figs. 5a,b) and the higher moisture contributions from the adjacent regions in January than July (Figs. 3a,b). The areaaveraged $\varepsilon$ values for January are lower than that for July during the first 5 days' tracking (Fig. 8 b) but are higher than that for July afterward (Fig. 8b). This characteristic can be explained by the different circulation patterns and related variables (Figs. 2c,d). The lower $P-\mathrm{Pw}$ ratio and higher wind speeds over China lead to less evaporation precipitating locally in January (Figs. 3c,d); however, in January, after leaving China, the residual evaporation quickly precipitates in regions with very high values of the $P-\mathrm{Pw}$ ratio, for example, the northwestern Pacific Ocean (Fig. 3c), which makes the 


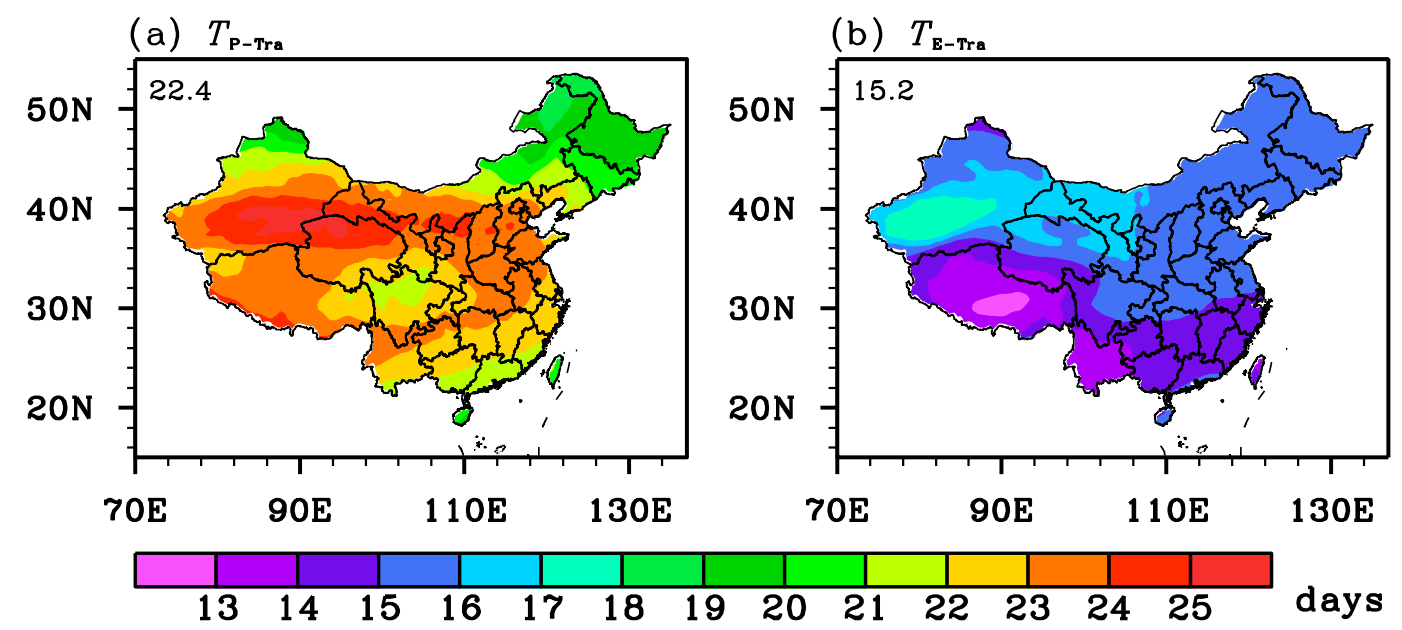

FIG. 7. The tracking times at the $90 \%$ threshold derived from 30 -yr-averaged ratios of attributed moisture to initial moisture (i.e., $\rho$ and $\varepsilon$ ) with the tracking time, with the area-averaged values denoted in the upper-left corners: (a) $T_{P \text {-Tra }}$ and (b) $T_{E-\text { Tra }}$.

proportion of attributed evaporation in January surpass that in July after 5 days' tracking. As a result, although the areaaveraged $T_{E \text {-Tra }}$ at the $90 \%$ threshold for January is approximately 3 days shorter than that for July (Fig. 8b), the area-averaged $T_{E \text {-Res }}$ values for January and July are approximately equal to each other (Figs. $5 \mathrm{c}$,d). The tracking times (Fig. 9) show quite similar spatial patterns with the moisture residence times (Fig. 5) in corresponding months, as well as some other similar characteristics. For example, the local $T_{P \text {-Tra }}$ for January is generally lower than that for July (Figs. 9a,b), as in agreement with the $T_{P \text {-Res }}$ results (Figs. 5a,b). The $T_{E \text {-Tra }}$ for July (Fig. 9d) shows a nearly opposite pattern compared with that for January (Fig. 9c), as is also consistent with the $T_{E \text {-Res }}$ results (Figs. $5 \mathrm{c}$,d). However, similar to the annual results, the spatial patterns of both $T_{P \text {-Tra }}$ and $T_{E \text {-Tra }}$ (Fig. 9) also have some differences with the $T_{P \text {-Res }}$ and $T_{E \text {-Res }}$ results (Fig. 5), respectively.

\section{d. The relationship between residence time and reference time for moisture tracking}

Given a longer moisture residence time for a certain region, investigations regarding moisture tracking would, practically, account for a longer tracking period of time. However, the setting of this period is a result of an empirical or trial-and-error process. The similar patterns and other characteristics between the tracking times (Figs. 7,9) and residence times (Figs. 4, 5) seem to imply that a proportional relationship exists between them. In this section, we investigate the explicit relationship between the moisture residence time and tracking time.

We first reveal the abovementioned relationship theoretically in the ideal situation. If the precipitable water and precipitation and evaporation rates are hypothesized to be constant along the trajectory, Eqs. (1) and (4) can be written as

$$
\rho(t)=1-\exp \left(-\frac{\bar{E}}{\bar{w}} t\right)
$$

and

$$
\varepsilon(t)=1-\exp \left(-\frac{\bar{P}}{\bar{w}} t\right)
$$

respectively. The time of any proportion of the initial moisture to be attributed, that is, the tracking time at the threshold of $\eta$, can be obtained from Eqs. (8) and (9):

$$
T_{V \text {-Tra }}(\eta)=\frac{\ln \left(\frac{1}{1-\eta}\right)}{a},
$$

where $V$ represents $P$ or $E, \eta$ denotes $\rho$ or $\varepsilon$, and $a$ stands for $\bar{E} / \bar{w}$ or $\bar{P} / \bar{w}$, correspondingly.

Under the ideal situation, the attributed moisture during each constant time step [i.e., $\Delta \rho$ in Eq. (2) or $\Delta \varepsilon$ in Eq. (5)] would decrease with the increase of the tracking time (Fig. 1). Now, we let the time step be changeable and set the attributed moisture during each time step $\Delta \eta$ to be constant, obtain the corresponding tracking time from Eq. (10), and then rewrite the equations for the residence time [i.e., Eqs. (6) and (7)] as

$$
T_{V-\operatorname{Res}}=\frac{\sum T_{V-\operatorname{Tra}}(\eta) \Delta \eta}{\sum \Delta \eta} .
$$



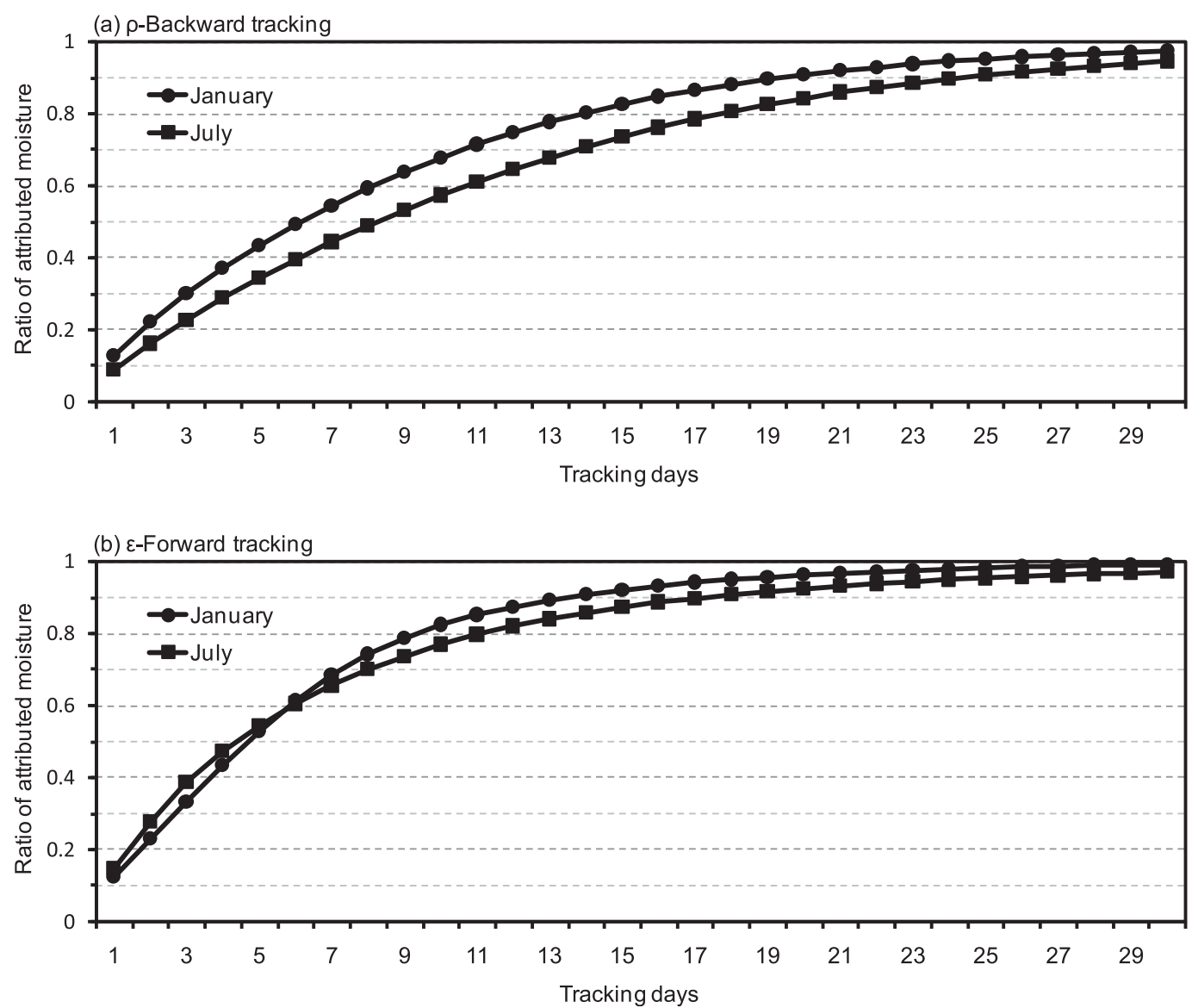

FIG. 8. The 30-yr mean and area-averaged ratios of attributed moisture to initial moisture in January and July as changing with backward- and forward-tracking days: (a) $\rho$ and (b) $\varepsilon$.

To obtain the exact atmospheric moisture residence time, all the initial moisture should be attributed. Thus, the upper bound of $\eta$ is set to be infinity close to 1 , and the proportion of attributed moisture during each time step $\Delta \eta$ is set to be infinitely small. Then, $\sum \Delta \eta$, which is the ratio of the total attributed moisture to the initial moisture, equals 1, and Eq. (11) can be written in the integral form:

$$
T_{V \text {-Res }}=\int_{0}^{1} T_{V \text {-Tra }}(\eta) d \eta .
$$

Substituting Eq. (10) into Eq. (12), the residence time can be explicitly expressed as

$$
T_{V \text {-Res }}=\frac{1}{a} .
$$

Table 1 summarizes the specific forms for Eqs. (8)-(13) for precipitation and evaporation. Note that the calculation of the moisture residence time [Eq. (13)] reduces to the traditional bulk method under the ideal situation, which means that the traditional bulk method can also be used to obtain the local residence time when the moisture condition (i.e., precipitable water and precipitation and evaporation rates) is constant along the trajectory. Considering that the traditional bulk method neglects the horizontal moisture flux, the assumption to obtain Eq. (13) appears to be more reasonable than that in the traditional bulk method. Then, the relationship between the residence time and tracking time can be described by a ratio (denoted as $r_{t}$ ) using Eq. (10) divided by Eq. (13), that is,

$$
r_{t}=\ln \left(\frac{1}{1-\eta}\right) .
$$

Equation (14) indicates that a certain proportional relationship exists between the two times and can explain the similar spatial patterns between them (Figs. 4 and 5 vs Figs. 7 and 9).

When reviewing previous works, Läderach and Sodemann (2016) indicated the link between the moisture residence 
(a) $T_{\text {P-Tra }}$ in January

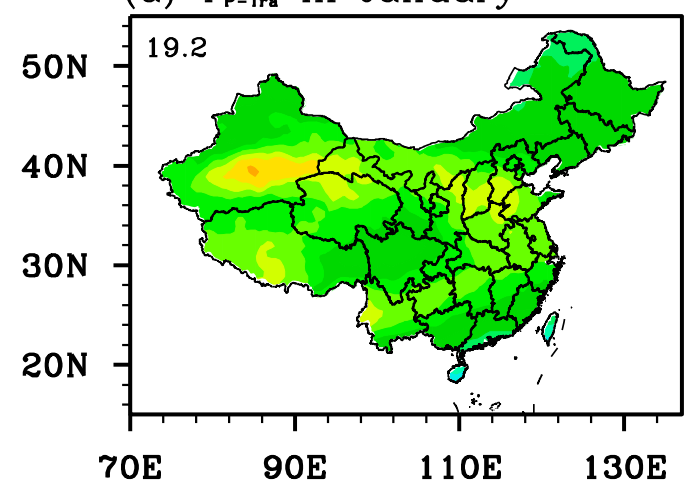

(c) $T_{\mathrm{E}-\mathrm{Tra}}$ in January

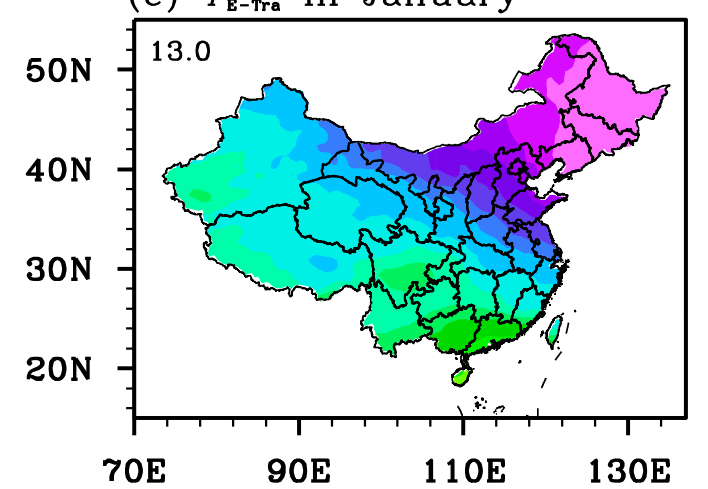

(b) $T_{\text {P-Tra }}$ in July

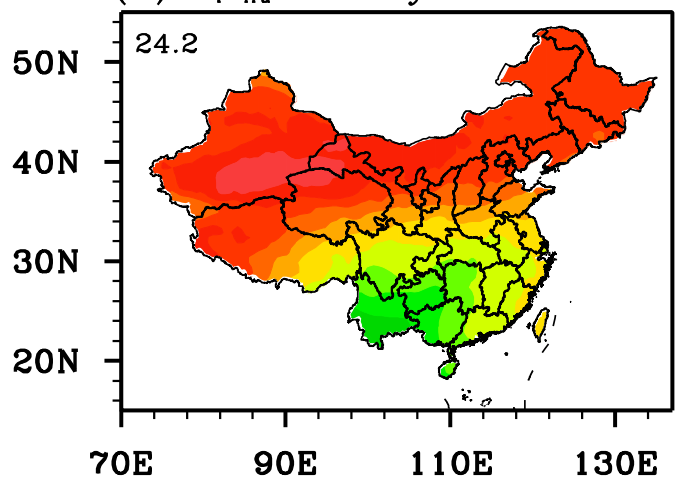

(d) $T_{\mathrm{E}-\mathrm{Tra}}$ in July

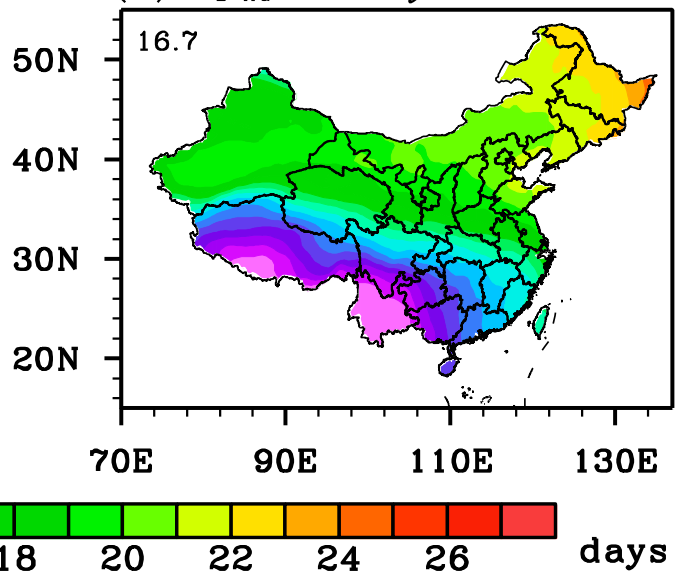

FIG. 9. The tracking times at the $90 \%$ threshold derived from 30 -yr averaged ratios of attributed moisture to initial moisture (i.e., $\rho$ and $\varepsilon$ ) with the tracking time for January and July, with the area-averaged values denoted in the upper-left corners: (a) January $T_{P \text {-Tra }}$, (b) July $T_{P \text {-Tra }}$, (c) January $T_{E \text {-Tra }}$, and (d) July $T_{E \text {-Tra. }}$.

time and $e$-folding time had not been established. In fact, this link was implicitly addressed by Trenberth (1998). Given that $\lambda$ is the depletion rate of precipitable water, $\lambda^{-1}$ is naturally the depletion time and equal to the $e$-folding time under some assumptions [see Trenberth (1998) for details]. Then in this study, we could reestablish the linkage between the moisture residence time and $e$-folding time from the perspective of moisture tracking by using Eq. (14). As noted above, the $e$-folding time is the tracking time during which $\left(1-e^{-1}\right)$ of initial moisture is attributed. Substituting $\eta=\left(1-e^{-1}\right)$ into Eq. (14), we obtain $r_{t}=1$. This indicates that the moisture residence time equals the $e$-folding time under the ideal conditions, as $r_{t}$ is the ratio of the tracking time to the residence time.

To verify the proportional relationship by Eq. (14), Fig. 10 shows the theoretical $r_{t}$ values under the ideal situation [calculated by the right side of Eq. (14)] and the DRM-derived $r_{t}$ values (which can be regarded as more realistic values), which change with the ratio of the attributed moisture to the initial moisture. The $r_{t}$ value increases with $\eta$ as expected [Eq. (14)], and the DRMderived values show a good agreement with the theoretical values, with the former slightly higher. There are two reasons that are possibly responsible for the slight difference: 1) the inherent difference between the DRM and ideal trackings, that is, the precipitable water and precipitation and evaporation rates are actually not constant along the trajectories and 2) the DRM-derived residence times are slightly lower than real values because of the residual moisture at the end of the trajectories. Note that the $r_{t}$ values of the forward tracking are closer to the ideal values than those of the backward tracking because the forward tracking attributed more moisture than the backward tracking (e.g., $98 \%$ versus $95 \%$ after 30 days' tracking; Fig. 6 ).

Figure 11 presents the $r_{t}$ distribution with the tracking time at the $90 \%$ threshold (Fig. 7 divided by Fig. 4). Clearly, the $r_{t}$ values for the forward tracking are generally around the theoretical values (Fig. 11b), while the 
TABLE 1. Summary of the specific forms for the calculations of the proportion of attributed moisture to initial moisture with the tracking time (attributed moisture), moisture tracking time at a certain threshold (tracking time), and moisture residence time in discrete (discrete residence time), integral (integral residence time), and explicit (explicit residence time) forms from the precipitation $P$ and evaporation $E$ perspectives under the ideal situation (see text for details of the symbols).

\begin{tabular}{|c|c|c|c|c|c|}
\hline & Attributed moisture & Tracking time & Discrete residence time & Integral residence time & Explicit residence time \\
\hline$P$ & $\rho(t)=1-\exp \left(-\frac{\bar{E}}{\bar{w}} t\right)$ & $T_{P-\operatorname{Tra}}(\rho)=\frac{\bar{w}}{\bar{E}} \ln \left(\frac{1}{1-\rho}\right)$ & $T_{P-\mathrm{Res}}=\frac{\sum T_{P \text {-Tra }}(\rho) \Delta \rho}{\sum \Delta \rho}$ & $T_{P-\mathrm{Res}}=\int_{0}^{1} T_{P-\mathrm{Tra}}(\rho) d \rho$ & $T_{P-\operatorname{Res}}=\frac{\bar{w}}{\bar{E}}$ \\
\hline$E$ & $\varepsilon(t)=1-\exp \left(-\frac{\bar{P}}{\bar{w}} t\right)$ & $T_{E-\operatorname{Tra}}(\varepsilon)=\frac{\bar{w}}{\bar{P}} \ln \left(\frac{1}{1-\varepsilon}\right)$ & $T_{E-\text { Res }}=\frac{\sum T_{E-\operatorname{Tra}}(\varepsilon) \Delta \varepsilon}{\sum \Delta \varepsilon}$ & $T_{E \text {-Res }}=$ & $T_{E-\operatorname{Res}}=\frac{\bar{w}}{\bar{P}}$ \\
\hline
\end{tabular}

$r_{t}$ values for the backward tracking are generally slightly higher than the theoretical values (Fig. 11a). The generally higher $r_{t}$ values for the backward tracking may be mainly caused by the second reason, as mentioned above. Meanwhile, the spatial differences may be mainly caused by the first reason, which is also responsible for the differences between the spatial patterns of the tracking time and residence time (e.g., Fig. 4 vs Fig. 7). The residence time is related to the attributed moisture during each time step [Eqs. (6) and (7)], while the tracking time is fully determined by the attributed moisture during the entire tracking period [Eqs. (1), (4), and (10)]. Thus, the $r_{t}$ values are probably higher (lower) if the trajectories attribute more (less) moisture than those of the ideal case during the initial tracking stage when a lower (higher) residence time is induced, for example, for the Tibetan Plateau (the Tarim basin) in Fig. 11.

\section{Conclusions and discussion}

This paper studies the atmospheric moisture residence time and tracking time over China with the NCEP CFSR data and the DRM moisture tracking model, in which the backward and forward trackings are used to calculate the residence times of precipitation and evaporation, respectively, and to obtain the corresponding tracking times. We provide the analytical expressions to calculate moisture residence times based on previous studies. In addition, we theoretically demonstrated the explicit expressions of residence time, tracking time, and the proportional relationship between the two times under the ideal condition.

The atmospheric moisture residence times are closely related to the processes involved in atmospheric moisture transport. The fact that precipitation is generally larger than evaporation over China causes local regions to account for a greater proportion of evaporation compared to precipitation. As a result, the local residence time of precipitation is generally longer than that of evaporation over China, with the area-averaged values of 8.3 and 6.3 days for $T_{P \text {-Res }}$ and $T_{E \text {-Res }}$, respectively. The $T_{P \text {-Res }}$ and $T_{E \text {-Res }}$ values are similar to those of van der Ent and Tuinenburg (2017) in both spatial pattern and magnitude and therefore indirectly support the traditional estimates of 8-10 days for global mean atmospheric moisture residence time.

The residence times have significant spatial variability with relatively long residence times of both precipitation and evaporation that appear over the Tarim basin and

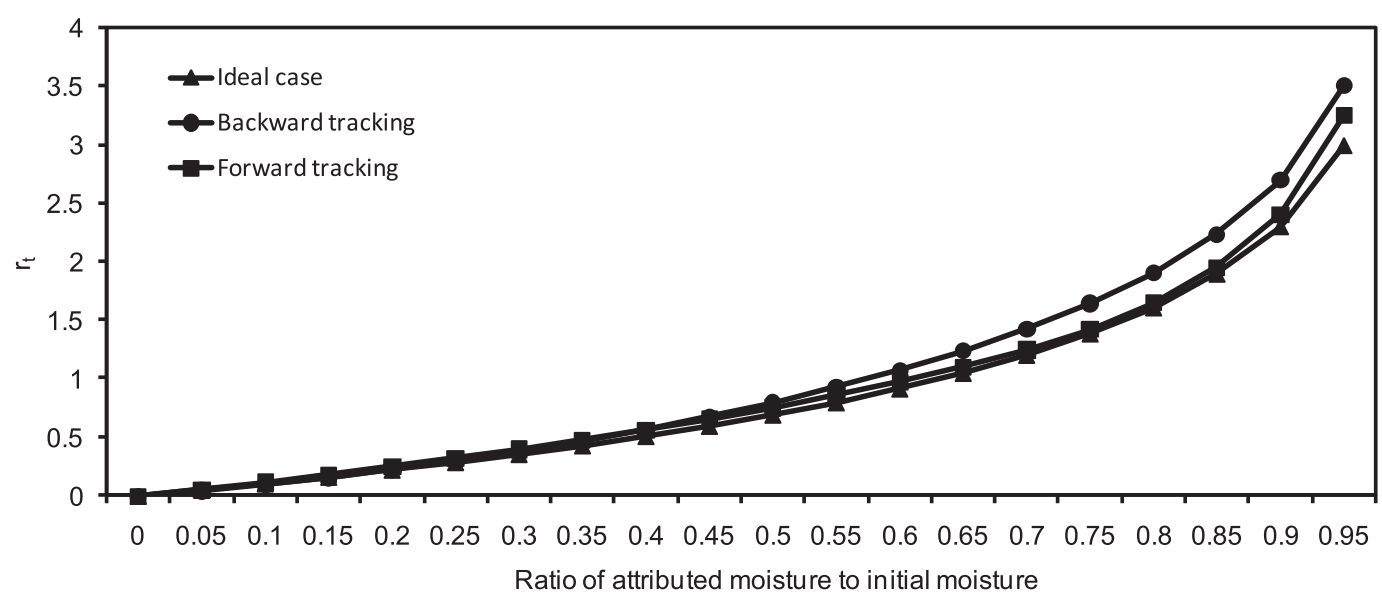

FIG. 10. Ratio $r_{t}$ of moisture tracking time to residence time calculated by the ideal case [Eq. (14)] and the DRM for the backward and forward trackings. 


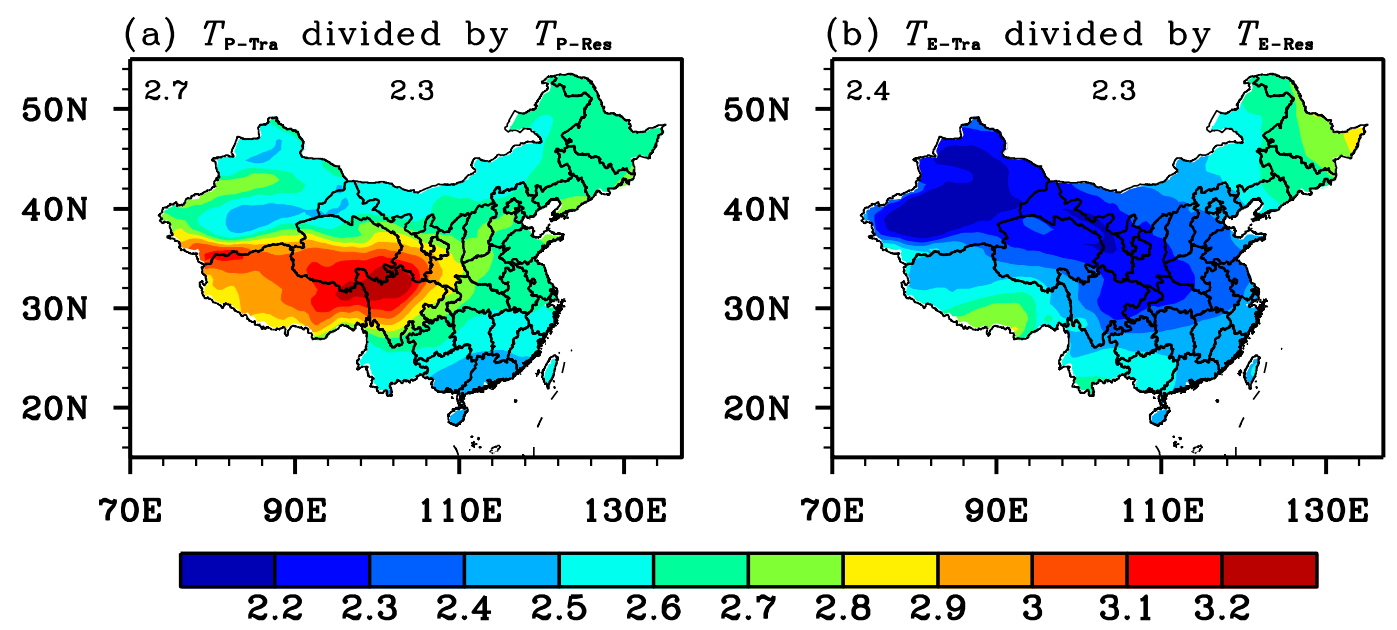

FIG. 11. Spatial distributions of DRM-derived $r_{t}$ in the (a) backward tracking and (b) forward tracking at the $90 \%$ threshold, with the area-averaged DRM-derived and ideal values denoted in the upper-left corners and the uppermiddle locations, respectively.

some other arid regions where evapotranspiration and precipitation are very low, and relatively short residence times of precipitation and evaporation exist over the Tibetan Plateau.

The precipitation and evaporation residence times also vary with season but in different aspects. The precipitation residence time remains with similar spatial patterns in summer and winter but apparently varies with season in magnitude, and the values in summer are generally higher than in winter over China. The evaporation residence time mainly varies with season in spatial pattern, with the evaporation residence time in summer showing a spatial pattern opposite to that in winter, together with relatively low values over the Tibetan Plateau and southwestern China in summer and over northeastern China in winter. These seasonal variations are caused by the changes in the circulation pattern and related moisture variables. As analyzed in section $3 \mathrm{a}$, for precipitation, the areas close to China provide a great deal of moisture during a relatively short time in winter, and the strong Asian summer monsoon circulation carries much moisture from remote oceanic areas (e.g., the southern Indian Ocean), which experience a relatively long residence time in summer. For evaporation, the circulation patterns and related variables are more likely to make evaporation from northeast China and southwest and south China quickly precipitate in winter and summer, respectively.

The area-averaged backward and forward tracking times at the $90 \%$ threshold are approximately 22 and 15 days, respectively. The tracking times show similar spatial patterns and some other characteristics with residence times.
Under the ideal situation, we found that the explicit expression of the moisture residence time reduces to the traditional bulk method. Then, we theoretically developed a proportional relation between the moisture residence time and tracking time (which is independent of tracking methods), that is, a lower (higher) moisture residence time agrees well with the lower (higher) tracking time, which is responsible for their similarities. This conclusion is further verified by the trackings using the DRM. However, the inconstant variables (i.e., precipitable water and precipitation and evaporation rates) along the trajectory can slightly, as a whole, lead to a deviation in the relationship. Moreover, using the proportional relation, we reestablished the linkage between the moisture residence time and the $e$-folding time in the context of calculating residence times by moisture tracking, that is, the moisture residence time equals the $e$-folding time under the ideal situation.

In addition to providing a theoretically robust basis for moisture tracking and enhancing our understanding of water cycling, the above proportional relations can, with the application of the moisture residence time, serve as a useful reference for the choice of tracking time, meeting the need to know how much initial moisture would be attributed. However, we note that the tracking time presented in the paper or obtained by the proportional relationship is the precise time for a certain proportion of attributed moisture. The choice of tracking time in actual studies should not be limited by this precise time, and a period that is a little longer than the precise time is a better choice. Moreover, the choice of tracking time should take into account the spatial variation, that is, it should be in accordance with the longest local residence time in the target region. 
Acknowledgments. This work was supported by the National Natural Science Foundation of China under Grants 41675007 and 41275012 and the Fundamental Research Funds for the Central Universities under Grant 2017B06214, all of which were granted to Dr. XinMin Zeng. We thank Dr. Francina Dominguez at the University of Illinois for the help in applying the dynamic recycling model, and we thank the editor and two anonymous reviewers for their helpful comments and suggestions in improving the manuscript.

\section{REFERENCES}

Bodnar, R. J., T. Azbej, S. P. Becker, C. Cannatelli, A. Fall, and M. J. Severs, 2013: Whole Earth geohydrologic cycle, from the clouds to the core: The distribution of water in the dynamic Earth system. The Web of Geological Sciences: Advances, Impacts, and Interactions, M. E. Bickford, Ed., Geological Society of America, 431-461, https://doi.org/10.1130/2013.2500(13).

Bosilovich, M. G., and S. D. Schubert, 2002: Water vapor tracers as diagnostics of the regional hydrologic cycle. J. Hydrometeor., 3, 149-165, https://doi.org/10.1175/1525-7541(2002)003<0149: WVTADO $>2.0 . \mathrm{CO} ; 2$.

— Y. Y. Sud, S. D. Schubert, and G. K. Walker, 2002: GEWEX CSE sources of precipitation using GCM water vapor tracers. GEWEX News, Vol. 12, No. 3, International GEWEX Project Office, Silver Spring, MD, 6-7, https://www.gewex.org/gewex-content/files_mf/ 1432150042Aug2002.pdf.

, S. D. Schubert, and G. K. Walker, 2005: Global changes of the water cycle intensity. J. Climate, 18, 1591-1608, https://doi.org/ 10.1175/JCLI3357.1.

Brubaker, K. L., D. Entekhabi, and P. S. Eagleson, 1993: Estimation of continental precipitation recycling. J. Climate, 6, 1077-1089, https://doi.org/10.1175/1520-0442(1993)006<1077: EOCPR > 2.0.CO;2.

Budyko, M. I., 1974: Climate and Life. Academic Press, 508 pp.

Burde, G. I., and A. Zangvil, 2001: The estimation of regional precipitation recycling. Part I: Review of recycling models. J. Climate, 14, 2497-2508, https://doi.org/10.1175/1520-0442(2001) 014<2497:TEORPR > 2.0.CO;2.

Chen, B., X. D. Xu, S. Yang, and W. Zhang, 2012: On the origin and destination of atmospheric moisture and air mass over the Tibetan Plateau. Theor. Appl. Climatol., 110, 423-435, https:// doi.org/10.1007/s00704-012-0641-y.

_ X.-D. Xu, and T. Zhao, 2013: Main moisture sources affecting lower Yangtze River Basin in boreal summers during 2004-2009. Int. J. Climatol., 33, 1035-1046, https://doi.org/10.1002/joc.3495.

Dee, D. P., and Coauthors, 2011: The ERA-Interim reanalysis: Configuration and performance of the data assimilation system. Quart. J. Roy. Meteor. Soc., 137, 553-597, https://doi.org/ 10.1002/qj.828.

Dirmeyer, P. A., and K. L. Brubaker, 1999: Contrasting evaporative moisture sources during the drought of 1988 and the flood of 1993. J. Geophys. Res., 104, 19383-19397, https://doi.org/ 10.1029/1999JD900222.

- , and - 2007: Characterization of the global hydrologic cycle from a back-trajectory analysis of atmospheric water vapor. J. Hydrometeor., 8, 20-37, https://doi.org/10.1175/ JHM557.1.

— C. A. Schlosser, and K. L. Brubaker, 2009: Precipitation, recycling and land memory: An integrated analysis. $J$.
Hydrometeor., 10, 278-288, https://doi.org/10.1175/ 2008JHM1016.1.

Dominguez, F., and P. Kumar, 2008: Precipitation recycling variability and ecoclimatological stability-A study using NARR data. Part I: Central U.S. Plains ecoregion. J. Climate, 21, 5165-5186, https://doi.org/10.1175/2008JCLI1756.1.

,,-- X.-Z. Liang, and M. Ting, 2006: Impact of atmospheric moisture storage on precipitation recycling. J. Climate, $\mathbf{1 9}$ 1513-1530, https://doi.org/10.1175/JCLI3691.1.

,$- \ldots$, and E. R. Vivoni, 2008: Precipitation recycling variability and ecoclimatological stability-A study using NARR data. Part II: North American monsoon region. J. Climate, 21, 5187-5203, https://doi.org/10.1175/2008JCLI1760.1.

_, G. Miguez-Macho, and H. Hu, 2016: WRF with water vapor tracers: A study of moisture sources for the North American monsoon. J. Hydrometeor., 17, 1915-1927, https://doi.org/ 10.1175/JHM-D-15-0221.1.

Douville, H., F. Chauvin, S. Planton, J.-F. Royer, D. Salas-Melia, and S. Tyteca, 2002: Sensitivity of the hydrological cycle to increasing amounts of greenhouse gases and aerosols. Climate Dyn., 20, 45-68, https://doi.org/10.1007/s00382-002-0259-3.

Drumond, A., R. Nieto, and L. Gimeno, 2011: A preliminary analysis of the sources of moisture for China and their variations during drier and wetter conditions in 2000-2004: A Lagrangian approach. Climate Res., 50, 215-225, https://doi.org/ 10.3354/cr01043.

Eltahir, E., and R. L. Bras, 1994: Precipitation recycling in the Amazon basin. Quart. J. Roy. Meteor. Soc., 120, 861-880, https://doi.org/10.1002/qj.49712051806.

Gimeno, L., A. Drumond, R. Nieto, R. M. Trigo, and A. Stohl, 2010: On the origin of continental precipitation. Geophys. Res. Lett., 37, L13804, https://doi.org/10.1029/2010GL043712.

_ , and Coauthors, 2012: Oceanic and terrestrial sources of continental precipitation. Rev. Geophys., 50, RG4003, https:// doi.org/10.1029/2012RG000389.

He, X., Y. Ding, J. He, and Q. Li, 2007: An analysis on anomalous precipitation in southern China during winter monsoon. Acta Meteor. Sin., 64, 594-604.

Hendriks, M. R., 2010: Introduction to Physical Hydrology. Oxford University Press, $352 \mathrm{pp}$.

Hoyos, I., F. Dominguez, J. Cannon-Barriga, J. A. Martinez, R. Nieto, L. Gimeno, and P. A. Dirmeyer, 2018: Moisture origin and transport processes in Colombia, northern South America. Climate Dyn., 50, 971-990, https://doi.org/10.1007/ s00382-017-3653-6.

$\mathrm{Hu}, \mathrm{H}$., and F. Dominguez, 2015: Evaluation of oceanic and terrestrial sources of moisture for the North American Monsoon using numerical models and precipitation stable isotopes. J. Hydrometeor., 16, 19-35, https://doi.org/10.1175/ JHM-D-14-0073.1.

$\mathrm{Hu}$, Q., D. Jiang, X. Lang, and B. Xu, 2018: Moisture sources of the Chinese Loess Plateau during 1979-2009. Palaeogeogr. Palaeoclimatol. Palaeoecol., https://doi.org/10.1016/ j.palaeo.2016.12.030, in press.

Hua, L., L. Zhong, and Z. Ke, 2017a: Characteristics of the precipitation recycling ratio and its relationship with regional precipitation in China. Theor. Appl. Climatol., 127, 513-531, https://doi.org/10.1007/s00704-015-1645-1.

,-- , and Z. Ma, 2017b: Decadal transition of moisture sources and transport in northwestern China during summer from 1982 to 2010. J. Geophys. Res. Atmos., 122, $12522-$ 12 540, https://doi.org/10.1002/2017JD027728. 
Huang, Y., and X. Cui, 2015: Moisture sources of torrential rainfall events in the Sichuan basin of China during summers of 2009 13. J. Hydrometeor., 16, 1906-1917, https://doi.org/10.1175/ JHM-D-14-0220.1.

Läderach, A., and H. Sodemann, 2016: A revised picture of the atmospheric moisture residence time. Geophys. Res. Lett., $\mathbf{4 3}$, 924-933, https://doi.org/10.1002/2015GL067449.

Lin, Z., 2016: Influence of the southern branch trough on plateau of southwestern China daily precipitation in wintertime (in Chinese). Plateau Meteor., 35 (6), 1456-1463.

Lorenz, C., and H. Kunstmann, 2012: The hydrological cycle in three state-of-the-art reanalyses: Intercomparison and performance analysis. J. Hydrometeor., 13, 1397-1420, https://doi.org/ 10.1175/JHM-D-11-088.1.

Martinez, J. A., and F. Dominguez, 2014: Sources of atmospheric moisture for the La Plata River basin. J. Climate, 27, 67376753, https://doi.org/10.1175/JCLI-D-14-00022.1.

Nieto, R., L. Gimeno, and R. M. Trigo, 2006: A Lagrangian identification of major sources of Sahel moisture. Geophys. Res. Lett., 33, L18707, https://doi.org/10.1029/2006GL027232.

Saha, S., and Coauthors, 2010: The NCEP Climate Forecast System Reanalysis. Bull. Amer. Meteor. Soc., 91, 1015-1057, https:// doi.org/10.1175/2010BAMS3001.1.

Savenije, H. H. G., 2000: Water scarcity indicators; The deception of the numbers. Phys. Chem. Earth B, 25, 199-204, https://doi.org/ 10.1016/S1464-1909(00)00004-6.

Simmonds, I., D. Bi, and P. Hope, 1999: Atmospheric water vapor flux and its association with rainfall over China in summer. J. Climate, 12, 1353-1367, https://doi.org/10.1175/1520-0442(1999)012<1353: AWVFAI $>2.0 . \mathrm{CO} ; 2$.

Sodemann, H., C. Schwierz, and H. Wernli, 2008: Interannual variability of Greenland winter precipitation sources: Lagrangian moisture diagnostic and North Atlantic Oscillation influence. J. Geophys. Res., 113, D03107, https://doi.org/ 10.1029/2007JD008503.

Stohl, A., C. Forster, A. Frank, P. Seibert, and G. Wotawa, 2005: Technical note: The Lagrangian particle dispersion model FLEXPART version 6.2. Atmos. Chem. Phys., 5, 2461-2474, https://doi.org/10.5194/acp-5-2461-2005.

Sun, B., and H. Wang, 2014: Moisture sources of semi-arid grassland in China using the Lagrangian particle model FLEXPART. J. Climate, 27, 2457-2474, https://doi.org/10.1175/JCLI-D-13-00517.1. , and —, 2015: Analysis of the major atmospheric moisture sources affecting three sub-regions of east China. Int. J. Climatol., 35, 2243-2257, https://doi.org/10.1002/joc.4145.

Trenberth, K. E., 1998: Atmospheric moisture residence times and cycling: Implications for rainfall rates and climate change. Climatic Change, 39, 667-694, https://doi.org/10.1023/A: 1005319109110.

Tuinenburg, O. A., R. W. A. Hutjes, and P. Kabat, 2012: The fate of evaporated water from the Ganges basin. J. Geophys. Res., 117, D01107, https://doi.org/10.1029/2011JD016221.

van der Ent, R. J., 2014: A new view on the hydrological cycle over continents. Ph.D. thesis, Delft University of Technology, 106 pp., https://doi.org/10.4233/uuid:0ab824ee-6956-4cc3b530-3245ab4f32be.

- , and H. H. G. Savenije, 2011: Length and time scales of atmospheric moisture recycling. Atmos. Chem. Phys., 11, 18531863, https://doi.org/10.5194/acp-11-1853-2011.
— , and O. A. Tuinenburg, 2017: The residence time of water in the atmosphere revisited. Hydrol. Earth Syst. Sci., 21, 779-790, https://doi.org/10.5194/hess-21-779-2017.

- H. H. G. Savenije, B. Schaefli, and S. C. Steele-Dunne, 2010: Origin and fate of atmospheric moisture over continents. Water Resour. Res., 46, W09525, https://doi.org/10.1029/ 2010WR009127.

—, L. Wang-Erlandsson, P. W. Keys, and H. H. G. Savenije, 2014: Contrasting roles of interception and transpiration in the hydrological cycle - Part 2: Moisture recycling. Earth Syst. Dyn., 5, 471-489, https://doi.org/10.5194/esd-5-471-2014.

Viste, E., and A. Sorteberg, 2013: Moisture transport into the Ethiopian highlands. Int. J. Climatol., 33, 249-263, https://doi.org/ 10.1002/joc.3409.

Wang, N., X.-M. Zeng, W. D. Guo, C. Chen, W. You, Y. Zheng, and J. Zhu, 2018: Quantitative diagnosis of moisture sources and transport pathways for summer precipitation over the mid-lower Yangtze River basin. J. Hydrol., 559, 252-265, https://doi.org/10.1016/j.jhydrol.2018.02.003.

Wei, J., P. A. Dirmeyer, M. G. Bosilovich, and R. Wu, 2012: Water vapor sources for Yangtze River Valley rainfall: Climatology, variability, and implications for rainfall forecasting. J. Geophys. Res., 117, D05126, https://doi.org/10.1029/ 2011JD016902.

, H. R. Knoche, and H. Kunstmann, 2016: Atmospheric residence times from transpiration and evaporation to precipitation: An age-weighted regional evaporation tagging approach. J. Geophys. Res. Atmos., 121, 6841-6862, https://doi.org/10.1002/ 2015JD024650.

Wen, M., Y. Yang, A. Kumar, and P. Zhang, 2009: An analysis of the large-scale climate anomalies associated with the snowstorms affecting China in January 2008. Mon. Wea. Rew., 137, 1111-1131, https://doi.org/10.1175/2008MWR2638.1.

Yoshimura, K., T. Oki, N. Ohte, and S. Kanae, 2004: Colored moisture analysis estimates of variations in 1998 Asian monsoon water sources. J. Meteor. Soc. Japan, 82, 1315-1329, https://doi.org/10.2151/jmsj.2004.1315.

Zeng, X.-M., M. Wang, N. Wang, X. Yi, C. Chen, Z. Zhou, G. Wang, and Y. Zheng, 2018: Assessing simulated summer $10-\mathrm{m}$ wind speed over China: Influencing processes and sensitivities to land surface schemes. Climate Dyn., 50, 4189-4209, https://doi.org/10.1007/s00382-017-3868-6.

Zhang, C., and Q. Li, 2014: Tracking the moisture sources of an extreme precipitation event in Shandong, China in July 2007: A computational analysis. J. Meteor. Res., 28, 634-644, https:// doi.org/10.1007/s13351-014-3084-9.

, Q. Tang, and D. Chen, 2017: Recent changes in the moisture source of precipitation over the Tibetan Plateau. J. Climate, 30, 1807-1819, https://doi.org/10.1175/JCLI-D-15-0842.1.

Zheng, Y., G. Yu, Y. Qian, M. Miao, X. Zeng, and H. Liu, 2002: Simulations of regional climatic effects of vegetation change in China. Quart. J. Meteor. Soc., 128, 2089-2114, https://doi.org/ 10.1256/003590002320603557.

Zhou, X. X., Y. H. Ding, and P. X. Wang, 2008: Moisture transport in the Asian summer monsoon region and its relationship with summer precipitation in China (in Chinese). Acta Meteor. Sin., 24 (1), 31-42. 